\title{
Persistent left superior vena cava connecting through coronary sinus to left-sided atrium
}

INSERM

\section{Source}

INSERM. (1999). Orphanet: an online rare disease and orphan drug data base. Persistent left superior vena cava connecting through coronary sinus to left-sided atrium.

ORPHA:99109

Persistent left superior vena cava connecting to the left-sided atrium is a rare, congenital vascular malformation of the major vessels characterized by a persitent left superior vena cava which drains directly to the left atrium, without passing through the coronary sinus (that may be absent in some cases). Patients are usually asymptomatic and discovered incidentally, however hypoxia, cyanosis, murmurs, palpitations, cardiac structural anomalies (e.g. atrial septal defect, bicuspid aortic valve, cor triatrium) and risk of paradoxical embolization may be associated. 